\title{
Occupational zoonoses in zoo and wildlife veterinarians in India: A review
}

\author{
H. B. Chethan Kumar ${ }^{1}$, K. M. Lokesha², C. B. Madhavaprasad ${ }^{3}$, V. T. Shilpa ${ }^{4}$, N. S. Karabasanavar ${ }^{5}$ and A. Kumar ${ }^{6}$
}

1. Division of Veterinary Public Health, Indian Veterinary Research Institute, Izatnagar, Bareilly, Uttar Pradesh, India. E-mail: chethuhb@gmail.com; 2. School of Public Health and Zoonoses, College of Veterinary Science, GADVASU, Ludhiana, Punjab, India. E-mail: lokeshvph@gmail.com; 3. Department of Veterinary Public Health and Epidemiology, Veterinary College, Shivamogga, Karnataka, India. E-mail: cbmadhava@rediffmail.com; 4. Department of Veterinary Pathology, Veterinary College, Hassan, Karnataka, India. E-mail: drshilpavt@gmail.com; 5. Department of Veterinary Public Health and Epidemiology, Veterinary College, Shivamogga, Karnataka, India. E-mail: docnagappa@rediffmail.com; 6. Principal Scientist and Head, Division of Veterinary Public Health, Indian Veterinary Research Institute, Izatnagar, Bareilly, Uttar Pradesh, India. E-mail: ashokakt@rediffmail.com

Corresponding author: H. B. Chethan Kumar, E-mail: chethuhb@gmail.com

Received: 27-02-2013, Revised: 14-04-2013, Accepted: 16-04-2013, Published online: 19-06-2013

\section{How to cite this article:}

Chethan Kumar HB, Lokesha KM, Madhavaprasad CB, Shilpa VT, Karabasanavar NS and Kumar A (2013) Occupational zoonoses in zoo and wildlife veterinarians in India, Vet World 6(9): 605-613, doi: 10.5455/vetworld.2013.605-613

\begin{abstract}
Zoos and biological parks are considered as a hub for public recreation and education. This is highlighted by the fact that visitors to the zoos are increasing year by year and they generate sizeable revenue. Veterinary professionals play a pivotal role in health management of wild animals in zoos and biological parks. Since veterinarians work in close contact with wild animals, there is a potential risk of transmission of zoonotic diseases from wild animals to humans and vice versa. There are approximately 1415 infectious agents causing diseases in humans, out of which $868(61 \%)$ are known to be zoonotic in nature. It is also important to note that more than $70 \%$ of the emerging zoonotic diseases have wild animals as reservoir hosts. The major zoonotic diseases that are transmitted from wild animals to humans include rabies, anthrax, leptospirosis, Q-fever, psittacosis, hendra virus, nipah virus, herpes B encephalitis, toxoplasmosis, etc. Hence, it is imperative for veterinarians and zoo staff to be fully aware of the knowledge pertaining to the source, transmission, pathogenicity, treatment and control of zoonotic diseases. In this manuscript, we provide key information regarding zoonotic diseases and also recommend important measures for their control and prevention. The information provided here will be highly beneficial for personnel who work in close association with wild animals.
\end{abstract}

Keywords: occupational hazards, veterinarian, wildlife, zoo, zoonoses

\section{I ntroduction}

Zoos and National Parks have long been considered as a hub for the conservation of wild animals as well as centres for public recreation and education [1]. From the professional point of view they are the potential sites of research for wildlife veterinarians, conservationists, wildlife biologists and epidemiologists. In India there are 102 national parks, 515 wildlife sanctuaries, 47 conservation reserves and 4 community reserves for the purpose of wildlife conservation [2]. In addition there are 198 zoos (including circuses) housing several species of wild mammals, birds, amphibians and reptiles [2,3]. According to Recognition of Zoo (Amendment) Rules, 2001 it is mandatory to appoint a veterinarian for the recognition of a zoo under the Wildlife Protection Act, 1972 [4]. The contribution of wildlife veterinarians in zoo management is invaluable since they apply their professional knowledge, skill and attributes for the betterment of habitat, nutrition, health and breeding of the captive wild animals [5].

Although the profession of wildlife veterinarians is exciting, it is also invariably challenging since it

This article is an open access article licensed under the terms of the Creative Commons Attribution License (http://creativecommons. org/licenses/by/2.0) which permits unrestricted use, distribution and reproduction in any medium, provided the work is properly cited. exposes them to numerous health-related risks in their day to day activities. A wide variety of health risks are usually encountered by wild life veterinarians viz., animal bites, back injuries, infections, adverse exposure to anaesthetic gases, needle stick injuries and even mortalities in certain cases $[6,7]$. The exposure to zoonotic diseases is one of the most important of such health risks for wildlife veterinarians by virtue of their occupation which demands a close association with wild animals. World Health Organization has defined zoonoses as 'those diseases and infections which are naturally transmitted between vertebrate animals and man [8]. There are about 1415 infectious agents causing diseases in humans, out of which 868 (61\%) are known to be zoonotic in nature [9]. It is also important to note that more than $70 \%$ of the emerging zoonotic diseases have wild animals as reservoir hosts [10]. Recently, there was an outbreak of Kyasanur Forest Disease (KFD) or monkey fever in macaques and langurs in bandipur tiger reserve, Karnataka and five personnel of the anti-poaching camp of the reserve fell ill with KFD. The disease was confirmed based on the analysis of blood samples collected from the animals by the National Institute of Virology, Pune [11].

\section{Wild animal infectious diseases as zoonoses}

Wild animals act as reservoirs for several zoonotic 
Table - 1. Major zoonotic diseases with relevance to wild animals [ Source: $12,19,25$ ]

\begin{tabular}{|c|c|}
\hline Agent & Zoonotic Disease \\
\hline $\begin{array}{l}\text { Bacterial, Rickettsial and } \\
\text { Chlamydial diseases }\end{array}$ & $\begin{array}{l}\text { Anthrax, Brucellosis, Campylobacteriosis, Colibacillosis, Ehrlichiosis, Leptospirosis, Lyme disease, } \\
\text { Melioidosis, Pasteurellosis, Plague, Salmonellosis, Tetanus, Tuberculosis, Q fever, Tularemia, Typhus, } \\
\text { Psittacosis, Murinetyphus, Relapsing fever, Rocky mountain spotted fever, etc. }\end{array}$ \\
\hline Fungal diseases & Aspergillosis, Coccidioidomycosis, Cryptococcosis, Dermatophytosis, Histoplasmosis, etc. \\
\hline Viral diseases & $\begin{array}{l}\text { Cercopithecine herpes virus } 1 \text { (B Virus Disease of Macaques), Colorado tick fever, Contagious ecthyma (Orf), } \\
\text { Buffalo pox, Crimean-Congo haemorrhagic fever, Equine encephalomyelitis, Foot-and-mouth disease, } \\
\text { Hantavirus pulmonary syndrome, Hendra virus infection, Hepatitis E, Influenza type A, Japanese encephalitis, } \\
\text { Kyasanur forest disease, Louping ill, Lymphocytic choriomeningitis, Murray Valley encephalitis, Newcastle } \\
\text { disease, Nipah virus infection, Rabies, Rift Valley fever, Russian spring-summer encephalitis, St. Louis } \\
\text { encephalitis, Tanapox, Viral Haemorrhagic Fevers, West Nile fever, Yabapox, Yellow fever, etc. }\end{array}$ \\
\hline Parasitic diseases & $\begin{array}{l}\text { Babesiosis, Balantidiasis, Chagas disease, Coenuriasis, Cryptosporidiosis, Cutaneous larva migrans, } \\
\text { Dirofilariasis, Giardiasis, Echinococcosis, Leishmaniasis, Malaria of nonhuman primates, Malayan filariasis, } \\
\text { Taeniasis, Toxoplasmosis, Trichinellosis, Trypanosomiasis, Visceral larva migrans, etc. }\end{array}$ \\
\hline
\end{tabular}

Table-2. Zoonotic diseases transmitted from different categories of wild animals [Source: 19,25]

\begin{tabular}{ll}
\hline Species & Disease transmitted \\
\hline Mammals & Anthrax, brucellosis, cat scratch disease, dermatophytosis, Glanders, Plague, Leptospirosis, Tuberculosis, Q \\
& fever, Rabies, Trichinellosis, Toxoplasmosis, Tularemia, Cryptosporidiosis, Listeriosis, Cysticercosis, Ebola virus, \\
& Marburg Virus, Echinococcosis, Viral encephalomyelitis, Escherichia coli, Slmonellosis, Lyme disease, Rat Bite \\
& Fever, Leishmaniasis, Rift valley fever, Rocky mountain spotted fever, etc. \\
Avians & Psittacosis, Avian tuberculosis, Campylobacteriosis, Erysipelothrix, Newcastle Disease, Salmonellosis, Avian \\
influenza, Cryptococcosis, Histoplasmosis, Q fever, etc. & \\
Reptiles and Amphibians & Campylobacter, Cryptosporidia, Salmonellosis, Q fever, Zygomycosis, Pentastomiasis, Spirometra \\
Aquatic creatures & (Sparganosis), Diphylobothrium, Mesocestoidiasis, etc. \\
& Aeromonas infection, Vibrio parahemolyticus, Salmonellosis, Mycobacteriosis, Erysipelothrix, \\
& Clostridium botulinum, Listeriosis, Clonorchis sinensis, Opisthorchis viverrini, Metagonimus yokogawai, \\
& Heterophyes heterophyes, Echinostoma hortense, Diphyllobothrium latum, Anisakiasis, Entero-viruses, \\
& astroviruses, calciviruses, Norwalk virus, etc.
\end{tabular}

diseases which could be bacterial, rickettsial, chlamydial, mycotic, viral and parasitic in their etiology (Table-1) [12]. It has been documented that more than $60 \%$ of the emerging human infectious diseases are zoonotic in nature of which more than $70 \%$ have wild animals as the reservoir hosts [13]. Table-2 summarizes an exhaustive but not the complete list of zoonotic diseases transmitted from different categories of wild animals to humans. Since ancient times, zoonotic diseases like plague, rabies and tuberculosis have devastated the mankind and interestingly all of them have wild animals as their reservoirs [14].

The symptoms of zoonotic diseases in humans may range from a self-limiting diseases which lasts for few days to long-term illnesses which may disable the person for several days even after the disease has been cured. For example, gastroenteritis caused by Salmonella spp., Cryptosporidium spp. and Giardia spp. are usually self-limiting [15]. Whereas, diseases like toxoplasmosis and Japanese encephalitis may end up causing abortions and fatal encephalitis, respectively. On the other hand, emerging viral diseases like Ebola and Marburg cause a high degree of mortality in the affected individuals [16].

Although zoonotic diseases have been viewed as serious threat to public health, they are also a major concern with respect to endangered species of wild animals which are on the verge of their extinction. Certain zoonotic diseases are fatal to their natural hosts and cause heavy mortality in the affected animals. For example, KFD and Ebola virus cause heavy mortality in monkeys and chimpanzees, respectively. Hence, zoonotic diseases pose a significant threat to the health of wild animals and also disturb the ecological balance and diversity [17].

In India, zoonotic diseases viz, leptospirosis, rabies, Japanese encephalitis, anthrax, brucellosis, bovine tuberculosis, cysticercosis, rickettsial infections and salmonellosis have been identified as 'priority zoonoses' which are to be targeted for their prevention and control [18]. The notable feature among these prioritized zoonotic diseases is that majority of them have either wild animals or wild birds as reservoirs. The zoonotic diseases such as anthrax, tuberculosis, rabies and several other diseases have been reported to occur in wild animals maintained in Indian zoos [19].

\section{Modes of disease transmission}

Each disease/causative agent has its own mode of transmission to reach and establish itself in a susceptible host (Table-3). Some diseases are unique in having only a single route of transmission (e.g. Trichinellosis is spread by consumption of infected meat) and some of the other diseases may have multiple routes of transmission (e.g. Tularaemia is spread by direct contact, contaminated food, water, aerosol and tick bites) [20]. The diseases which are transmitted from animals to humans are scientifically termed as anthropozoonotic diseases, the best examples being anthrax, rabies and psittacosis. On the other hand, those diseases which are transmitted from humans to animals are termed as zooanthroponotic diseases. Human type tuberculosis, measles, herpes simplex virus 1 , giardiasis and entamoeba are the common zooanthroponotic diseases [21]. Under wild life settings such as zoos, both anthropozoonotic and zooanthroponotic transmission can efficiently occur which is clearly evident from various studies [22]. Although, anthro- 
Table -3. Zoonotic diseases and their routes of transmission [Source: 20,25]

\begin{tabular}{ll}
\hline Routes of transmission & Zoonotic Diseases \\
\hline Oral & Baylisascariasis, Campylobacteriosis, Chlamydiosis, Cryptosporidiosis, Escherichia coli O157:H7, \\
& Echinococcosis, Giardiasis, Hookworms, Larva Migrans, Salmonellosis, Toxoplasmosis, Trichinellosis, \\
Yersiniosis, etc. & \\
Bespiratory & Bistetella Infection, Cryptococcosis, Hantavirus, Melioidosis, Nipah, Plague, Psittacosis, Q Fever, Tularemia, \\
DirectContact & Anthrax, Avian Influenza, Brucellosis, Cat Scratch Disease, Dermatophytosis, Glanders, Leptospirosis, \\
& Mycobacteriosis, Nipah, Pasteurellosis, Plague, Q Fever, Rabies, Rat Bite Fever, Sporotrichosis, \\
Vector-borne & Streptococcosis, Tularemia, etc. \\
& Plague, West Nile Encephalitis, Ehrlichiosis, Leishmaniasis, Lyme Disease, Q Fever, Rocky Mountain Spotted \\
Vertical route & Fever, Tularemia, Trypanosomiasis (Chagas' disease), Crimean Congo Haemorrhagic Fever, Yellow fever, \\
Viral encephalomyelitis, Japanese encephalitis, etc. & \\
Multiple routes & Brucellosis, Toxoplasmosis, African trypanosomiasis, Listeriosis, Tuberculosis, Japanese encephalitis virus, \\
& Nipah virus, etc. \\
& Lyme disease, Qfever, Tularemia, Listeriosis, etc.
\end{tabular}

pozoonotic diseases have been studied extensively, relatively little work has been done with respect to zooanthroponotic diseases in zoo settings [21,23].

The knowledge pertaining to disease transmission is important, because the manifestation of disease symptoms differs depending on the route of transmission and the knowledge gained regarding these aspects is also helpful for introducing effective prevention and control strategies by breaking the transmission cycle. The common modes of disease transmission include a direct mode (direct skin contact, ingestion, inhalation, animal bites and needle stick injuries) and an indirect mode (fomite, vector borne and long distance airborne transmission).

\section{Factors governing the spread of zoonotic diseases in wildlife settings}

For the successful establishment of disease in a host, there must be a balanced interaction between the disease causing agent, the susceptible host and the environment in which both the agent and host thrive [24]. The agent must evade physical, biological and immunological barriers of the host before it can establish itself and cause the disease. The host-related factors like species, sex, age, breed and genetic composition will make the host either susceptible or resistant to a disease. The reasons for restriction of certain zoonotic diseases to a particular geographical area could be primarily explained by the prevailing environmental factors like temperature, vegetation, rainfall, humidity, altitude and availability of vectors [25].

Negligence of veterinarians and zoo staff toward the use of personal protective equipment during treatment, necropsy, cleaning the animal enclosures and improper hand hygiene will increase the chances of disease transmission [26]. In a survey of Indian wildlife veterinarians it was learnt that nearly $16.7 \%$ respondents didn't take any precautions and only $16.7 \%$ veterinarians took proper precautions while handling the wild animals [27]. The study also identified that only 34 out of 54 veterinarians surveyed were prophylactically vaccinated against rabies. India is the leading country with regard to human deaths due to rabies and the vaccination status (only $62.9 \%$ ) of the respondents in the survey is definitely a matter of concern and is an alarming situation because wildlife veterinarians are at a high risk of acquiring rabies [28, 29].

Unscientific methods of disposal of wild animal carcasses, organs, feces, urine and unused food serves as sources of pathogens and enhances vector breeding which then favours the disease transmission [30]. Entering into the core areas of the national parks and forests for the purpose of wild animal census, wildlife rehabilitation, epidemiological investigation and geographical survey may expose wild life veterinarians to arthropod bites which are vectors for transmission of tularaemia, Crimean Congo Haemorrhagic Fever and several other zoonotic diseases.

Overcrowding, improper restraining methods, change in food habits and transport of wild animals to a new environment induces stress in the animals. The stress leads to overt disease, which may subsequently spread to other inmates of the zoo and to the zoo personnel [31]. Paucity of knowledge on specific aspects like carrier status, disease susceptibility and natural micro-flora of new species of animals poses numerous problems. This situation particularly arises when a new species of wild animal from a foreign country is introduced into the zoo as a part of wild animal exchange programmes [31]. The existence of asymptomatic carrier status for certain zoonotic infectious diseases in wild animals generally go unnoticed and hence act as a potential source of zoonotic spread [32].

Lack of good laboratory practices and standard operating procedures while handling clinical samples viz., blood, urine, feces and biopsy materials in wildlife disease diagnostic laboratories would lead to infections in the laboratory personnel. A laboratory technician who became seropositive for Q-fever after getting exposed to the clinical material is one such example for improper handling of clinical materials [33].

\section{Zoonotic diseases in wildlife veterinarians and zoo personnel}

Although sizeable literature is available on the prevalence of zoonotic diseases in field veterinarians, only one report is available regarding occupational hazards encountered by wild life veterinarians in India. 
In the survey of wildlife veterinarians conducted by Nigam and Srivastav [27], only two among fifty four wildlife veterinarians reportedly contracted the zoonotic disease. However, it is likely that the prevalence of zoonotic diseases in wildlife veterinarians could be even higher than the reported prevalence in the above reported survey (only 3.7\%). The low prevalence shown could be largely due to under reporting or hesitation by the veterinarians to disclose their past or current disease status [27].

Veterinarians and zoo staff come in direct contact with wild animals during clinical examination, blood collection, biopsy procedure, surgery, hand rearing of new born animals and post-mortem examinations. These occupational interventions leave them exposed to the risk of contracting zoonotic diseases. An outbreak of methicillin resistant Staphylococcus aureus (MRSA) infection took place in San Diego County zoo, where zoo personnel acquired MRSA infection from an elephant calf by virtue of their close contact. The affected personnel suffered from cutaneous pustules and cellulitis [34]. Frequently, mycotic skin infections are also acquired through direct contact with the infected animals. A survey conducted by Epp and Waldner revealed ringworm infection in $7.6 \%$ of the veterinarians [35].

Lack of proper personal hygiene and ingestion of food and water contaminated with feces and urine of diseased animals is the leading cause of various gastrointestinal infections. Salmonella spp., E. Coli., Campylobacter spp., Giardia spp., Entamoeba spp., Cryptosporidium spp. and Toxocara spp. are the major gastroenteritis-causing agents isolated from wild animals [36]. Such reports frequently come from zoos where poor hygiene and sanitation practices exist. To complicate the situation, the animals infected with aforementioned pathogens may remain asymptomatic but continue to shed pathogens in their feces, urine and saliva. Such secretions and excretions contaminate the nearby enclosures, thus spreading the disease to other susceptible animals, veterinarians, zoo staff and visitors of the zoo [37]. For example, an outbreak of salmonellosis was recorded in the visitors of Colorado zoo. The source of outbreak was traced back to an infected komado dragon which had contaminated the wooden barrier and those visitors who came in direct contact with the wooden barrier then became the victims of the outbreak [38]. The prevalence of zoonotic enteritic organisms in zoo animals and their potential risk can be estimated from cases of gastroenteritis in visitors after handling animals in petting zoos $[39,40]$. An animal attendant in Vienna zoo acquired shigellosis infection and suffered from bloody diarrhoea. The worker got infected while cleaning the animal house of Orangutans that died of shigellosis [41].

Inhalation of dust, aerosols and droplet nuclei generated from diseased animals is another important route of transmission for zoonotic diseases such as tuberculosis, chlamydiosis and influenza. Chlamydiosis is a disease of birds caused by Chlamydia psittaci, which is shed through the nasal discharge and droppings. Human infection is contracted through inhalation of contaminated dust and fecal particles. The disease is usually self-limiting with flu-like symptoms, but in untreated patients and complicated cases it may progress into fatal pneumonia and a multi-organ dysfunction may ensue. An outbreak of zoonotic psittacosis which took place in Japan affected several farm workers and visitors of the aviary. During epidemiological investigation of the outbreak it was found that the workers of the two aviaries had no knowledge of psittacosis $[42,43]$. In another outbreak, five animal attendants suffered with psittacosis after assisting a Siberian moose during parturition in a zoo at Kanagawa, Japan. The probable source of infection was inhalation of droplets produced during the act of parturition and contact with placenta and birth fluids [44]. A rare case of zoonotic psittacosis infection contracted during endoscopy of an infected parrot is also available in the literature [33].

It is not uncommon for a veterinarian to get bitten by animals. Procedures like restraint and clinical examination involve inherent risk of scratches and bites [27]. Such scratches and wounds inflicted by diseased animals may prove fatal, if neglected. The nature of the bites may vary from non-bleeding scratches to severe injuries which require immediate medical attention. Bites, scratches and fractures are the major occupational hazards experienced by wildlife veterinarians in India [27]. A survey of practicing veterinarians conducted in Western Canada revealed that veterinarians are often prone to bite injuries from animals. This is indicated by the fact that out of 809 respondents, 586 veterinarians reported either being bitten, scratched, or both by animals [35]. According to this study animal bite was the most frequent biological hazard experienced by veterinarians in Western Canada. Many diseases are transmitted through animal bites, with rabies being the classical example. Several mammals including wild animals are reservoirs for rabies. In India wild animal's viz., mongoose, jackals and monkeys act as reservoirs of rabies and some of these cases were recorded from wildlife parks and zoos. [45]. Other major diseases which spread through animal bites are tetanus, tularaemia and simian B herpes virus.

Several species of arthropods such as mosquitoes, ticks, mites and fleas are incriminated as vectors in transmission of zoonotic diseases. Q-fever, lyme disease, tularaemia, west nile fever and Crimean Congo haemorrhagic fever (CCHF) are few examples of important vector borne diseases [46]. Several species of wild animals and birds act as reservoirs for the aforementioned diseases and are considered as emerging zoonotic diseases in certain parts of the world [47]. The outbreak of CCHF which took place in Gujarat state in the year 2011 and claimed lives of four 
people is a fresh example of emergence of arboviral diseases in India [48].

Unlike humans, animals are not highly cooperative during clinical procedures. Thus, it is not surprising for a veterinarian to get accidental needle stick injuries. According to the available literature, needle stick injuries can have a prevalence of up to $75 \%$ among the veterinary health professionals [49]. Needle stick injuries can lead to Staphylococcus infection, herpesvirus simiae infection and blastomycosis. A veterinary technician who got infected with herpes virus simiae from Rhesus monkey due to a needle stick injury is an example for such accidents [50]. In another report, Ramsey described blastomycosis in a veterinarian as a consequence of needle stick injury [51].

Coxiella burnetti which is considered as an emerging or re-emerging zoonosis has multiple routes of transmission and the disease was detected in two zoo veterinarians after they came into contact with a diseased fallow deer in Stuttgart, Germany. The wife of one of the two infected veterinarians also contracted the disease, probably by handling the contaminated clothes. This shows the significance of horizontal transmission of zoonotic diseases to other members of the community through diseased persons [52].

A case of cercopithecine herpesvirus 1 (B Virus) transmitted from a Rhesus macaque to a female worker has been recorded in a primate centre in USA. The faecal material was splashed into the eye of the worker while she was attempting to handle the macaque. The affected worker initially exhibited ocular symptoms followed by progressive paralysis and death after 42 days of infection [26].

Tuberculosis, an ancient disease, is the cause of death of several people in India annually. Many species of wild animals (especially non-human primates) and birds have been implicated as sources of tuberculosis infection to wildlife professionals. Epidemiological reports which are suggestive of animal to human and human to animal transmission of tubercle bacilli in wildlife settings are also available indicating the potential risk to zoo veterinarians and other staff $[53,54]$.

\section{Prevention and control of zoonotic diseases in wildlife settings}

Report of brainstorming meeting on road map to combat zoonoses in India (RCZI) organised by Public Health Foundation of India (PHFI) has stressed wildlife sector as one of the important disciplines which should be given due importance to achieve the goal of 'One Health'. It has also addressed active involvement of wildlife institutes, wildlife functionaries and wildlife experts as a part of multidisciplinary group for prevention and control of zoonotic diseases in India [18].

The prevention and control of zoonotic diseases must be an integral part of zoo occupational health and safety measures. Because treatment of zoonotic diseases in wild animals is an additional burden to the veterinarians and other zoo staff, a preventive approach is best. Preventive approaches can be either general or specifically designed for a particular disease condition. Just by following basic hygiene and sanitation procedures it is possible to prevent many of the zoonotic diseases. An effective disease control strategy should essentially address three vital aspects viz., host, agent and environment.

\section{I nfection control strategies for animal host}

Susceptibility of an animal to a particular etiological agent varies between different species and also between the members of the same species. Furthermore, neonates, geriatric, malnourished, pregnant, stressed and immune-compromised animals are more vulnerable to a disease. A disease can propagate in an animal population when susceptible animals exist; and by reducing the number of susceptible animals to a critical threshold level, the propagation of disease can be halted. This task can be achieved through two main strategies; vaccination of the susceptible animals and treatment of the diseased host. Vaccination increases the number of immune animals in a herd, thereby conferring immunity to the herd and eventually decreasing the number of secondary cases i.e. reduced basic reproductive ratio $\left(\mathrm{R}_{0}\right)$. When $\mathrm{R}_{0}$ is less than one, the pathogen ceases to transmit between the individuals and subsequently gets eliminated from the population [55].

In addition to immunization, other strategies to reduce susceptible host population for the purpose of containing the spread of the disease include translocation of susceptible animals; test and slaughter of infected animals; selective depopulation of reservoir hosts and fertility control [56]. However, these strategies are of relevance to controlling the disease in free living wildlife rather than in captive species.

Vaccination is an effective strategy to reduce the number of susceptible animals in a population by increasing the resistance to the disease via enhancing the herd immunity. Vaccination of wildlife in the form of oral baits was pivotal in the control and elimination of rabies in many European countries [57]. However, vaccination may not be the final answer for the prevention and control of all infectious diseases. It can be used only for a few diseases because of inherent limitations in the vaccine efficacy, safety, duration of immunity and economic considerations [58]. Indian zoos are maintaining a regular vaccination and deworming schedule against different infectious diseases, but it seems to vary from one zoo to another and also varies according to the species of wild animals housed in the zoos. In Indian zoos, vaccination of herbivores is performed against diseases such as haemorrhagic septicaemia, black quarter and foot and mouth diseases twice a year. Annually, felines and canine species are immunized against rabies, feline panleucopenia, feline viral rhinotracheitis, feline calci 
virus, leptospirosis, canine distemper and parvovirus. In addition, once in three months, prophylactic vaccination is performed against trypanosomiasis in felines. Lasota vaccine is administered to birds against Newcastle disease (Drs. L.M. Kshamaa, and Komal Powar, through personal communication).

Another way to protect the susceptible segment of population from disease is by preventing exposure to the source of infection viz., diseased animals and asymptomatic carriers. The prompt isolation and treatment of diseased animals will reduce the infectiousness of the host, dose of shedding and hence prevents exposure of susceptible animals to pathogens [58].

Since wild animals are known to carry a variety of zoonotic pathogens in an asymptomatic state, efforts should be made to periodically screen the animals for disease conditions. Regular deworming is necessary, because animals are susceptible to re-infection with variety of parasites after the initial round of deworming [59].

Whenever new animals are introduced into the zoo as a part of animal exchange programme between different zoos, quarantine must be strictly followed for a specific period of time to ensure that the newcomers are free from infectious diseases [19]. Otherwise, the newly introduced animals may act as sources of infection to the existing inmates of the zoo.

All animals in captivity should receive adequate quantity of wholesome, safe and nutritious food and water. Since, sufficient quantities of energy and protein are necessary for efficient functioning of the immune system, the diet must be adequate to meet these requirements. Stress, which could be either physiological or pathological, will hinder the effective functioning of the immune system thereby rendering the host susceptible to infectious agents [60]. Hence, during transportation, restraint, physical examination and treatment, precautions should be taken to minimize the stress levels.

The captive animals should be trained by skilled trainers such that they cooperate voluntarily during the routine clinical procedures. Such behavioural training minimizes stress to animals in addition to decreasing the chances of occupational injury to veterinarians and zoo staff involved in such procedures [61].

Surveillance is an important tool for the purpose of collection, analysis and interpretation of data with respect to health and disease status in an animal population. It also aids in gaining knowledge regarding the temporal and spatial trends of the disease. Therefore, active and passive surveillance involving collection of specimens from live and dead animals is necessary for laboratory diagnosis [62].

\section{Environmental control}

Environment encompasses all those conditions that surround the animals which include both abiotic and biotic components. Factors such as temperature, humidity, rainfall, landscape and vegetation all have either a direct or an indirect bearing on survival and perpetuation of the disease-causing agent. The main goal of environmental manipulation lies in creating the conditions unfavourable for survival of pathogens and reducing the perpetuation of vectors.

Many pathogens spend part of their life cycle in the environment from where the host can contract the infection. Infective stages like bacterial and fungal spores, parasitic ova, larvae, cysts and oocysts are known to survive for months to years in environmental extremes and hence can act as sources of infection for prolonged periods of time [63, 64]. Improper disposal of manure, excretions and secretions of diseased animals builds up a quantum of infection in the immediate vicinity of the zoo and hence is a potential public health concern for zoo staff and to the visitors of the zoo. Therefore, environmental hygiene and sanitation should be addressed in zoo bio-security plan. The infective stages present in cages, enclosures, and other fomites should be destroyed by either chemical or physical methods of disinfection [60].

Unscientific management of plants, vegetation, lakes and ponds in the zoo may become potential breeding sites for arthropods vectors viz., mosquitoes, ticks, fleas and mites which are known to transmit several zoonotic diseases such as equine encephalitis, west nile fever and plague. Drying of marshy areas, scientific waste disposal, protecting the water bodies and destruction of unwanted vegetation will ensure freedom from arthropod breeding. The pest management strategy should be based on an integrated approach that involves physical, biological and chemical methods [65].

Captive animals should be provided with sufficient floor space so that they can roam around freely to get adequate physical activity. Captivity should be made as comfortable as possible by providing enriched enclosures to protect the inmates from environmental extremes and predators which may otherwise be a reason for stress and subsequent immunosuppression [60].

All efforts should be made to prevent the spill over of pathogens from wild animals to domestic animals and their further spread to humans [66]. Hence, enclosures and barriers such as fencing should be constructed in and around the zoo to prevent contact between inmates of the zoo and stray animals [67].

\section{Infection control strategies for veterinarians and zoo staff}

Because of the close proximity with captive animals, often time's vets and zoo staff become the victims of the zoonotic pathogens. It is important to know that since past few decades many of the zoonotic pathogens have emerged from wildlife resulting in grave consequences. Hence, wildlife veterinarians and zoo staff must have sound knowledge regarding zoonotic diseases, particularly with respect to 
reservoirs, transmission, clinical symptoms and their prevention and control measures.

Proper physical and chemical restraint of wild animals is necessary to avoid fear, apprehension and bites. Mandatory use of personal protective equipment like gloves, mask, face shield, apron while performing veterinary procedures and during cleaning of animal enclosures should be strictly enforced. These physical barriers lessen the chances of exposure of human skin and mucus membranes to the infective materials and accidental needle stick injuries [68].

Zoo staff should be screened for the presence of zoonotic diseases once in a year and the affected personnel should be treated accordingly [69]. Veterinarians and other zoo staff coming in contact with animals must receive prophylactic vaccination against infectious diseases like rabies, tetanus, influenza, hepatitis A and B [33,68,70]. Regular deworming is also necessary for veterinarians and zoo staff.

Wildlife veterinarians and zoo staff should wear insecticide-impregnated clothing and apply insect repellents to the exposed body parts to protect themselves from vector bites [71].

Establishment of a network of laboratories for rapid diagnosis of wildlife diseases is necessary at zoo, regional and national levels [72]. Well trained personnel and good laboratory practices are necessary for wildlife disease diagnostic laboratories. Eating and drinking should be prohibited inside the diagnostic laboratories.

With respect to the knowledge of wildlife medicine, the current undergraduate veterinary curriculum addresses important aspects that describe physiology, behaviour, nutrition, disease prevention and control in wild animals. However, it has been suggested that the curriculum should also give additional insights into areas viz., wild animal rehabilitation, conservation biology, epidemiology and ecology. There are only few veterinary universities and institutes in India which offer post graduate specialization in wildlife medicine. Wildlife medicine is an emerging discipline and hence, training and refreshment courses are the need of the hour to those veterinarians who choose wildlife and zoological medicine as their carrier [73].

Interdisciplinary collaboration between wildlife veterinarians, medical professionals, biologists, epidemiologists and conservationists is necessary for proper planning of zoo activities and for sharing of knowledge regarding wildlife management. In a similar effort, Indian Veterinary Research Institute (IVRI) in collaboration with Central Zoo Authority (CZA) has developed guidelines and protocols for diagnosis and treatment of wild animal diseases [18]. With the initiation of "Small Grant Fellowship" by CZA of India, there is an opportunity for zoo veterinarians to take up research projects at the zoo level. These small grant fellowships should be utilized at best, for research in scientific management of wild animals through which several aspects of zoonotic diseases viz., etiology, epidemiology, pathogenesis, prevention and control could be studied at the zoo level.

Majority of the visitors to the zoo may not be aware of the diseases that are transmitted from wild animals to humans. In this regard, public education must be undertaken by forest and zoo authorities through displaying signage boards, distribution of leaflets containing information on disease threats and also by organizing awareness programmes to school children and zoo visitors. Efforts should be taken to provide adequate number of hand washing facilities inside the zoo premises. The food catering area should be well-separated from animal enclosures.

Readers are advised to consult excellent reviews $[37,56,58,60]$ for further information on disease prevention and control strategies in wild animals.

\section{Conclusion}

Zoonotic diseases have always been a threat to mankind by causing enormous productive and economic losses. In addition, loss of man power, work hours and money spent on medical care adds to the burden of zoonotic diseases. Above all, the pain, agony and isolation from social life are the few of the adverse consequences of any zoonotic disease. Further, the diseased person may act as a source of infection to the community. Wild animals which harbour diverse group of zoonotic agents pose threat to the veterinarians, zoo staff and visitors of the zoo. The previous surveys of zoo and wildlife veterinarians have revealed that zoonotic diseases contributes up to $30 \%$ cases among the overall occupational illness reported in zoos. In addition, zoonoses have been a threat to the diversity of wild animals in a country because they do result in heavy mortality in wild animals. A complete knowledge of etiology, transmission, reservoirs and vectors of zoonotic diseases is therefore absolutely necessary. Finally, the prevention and control of zoonotic diseases must be an integral part of zoo occupational health and safety measures.

\section{References}

1. Cuaro'n, A. D. (2005) Further Role of Zoos in Conservation: Monitoring Wildlife Use and the Dilemma of Receiving Donated and Con? scated Animals. Zoo Biology, 24: 115124.

2. Ministry of Environment and Forests (MoEF), (2012) Annual Report 2011-12. Government of India. Environmental Information System (ENVIS), New Delhi, pp. 386.

3. Central Zoo Authority (CZA), (2010) Inventory of animals in Indian zoos and animal profile of identified individual of endangered wild animal species, 2009-10. Kamal printers, New Delhi, pp. 598.

4. The Wildlife (Protection) Act (WPA), (1972) The Wildlife (Protection) Amendment Act, 2002. Ministry of Law and Justice.

5. Kumar, H.R. and Srivatsav, U.C. (2010) The zoo veterinary profession: challenging, interesting, vibrant and fulfilling. Zoo's print, 25(6): 15-16.

6. Hill, D.J., Langley, R.L. and Morrow, W.M. (1998) Occupational injuries and illnesses reported by zoo veterinarians in the United States. J zoo wildl Med, 29(4): 
371-385.

7. Kabuusu, R.M., Keku, E.O., Kiyini, R. and McCann, T.J. (2010) Prevalence and patterns of self-reported animalrelated injury among veterinarians in metropolitan Kampala. $J$ Vet Sci, 11(4): 363-365.

8. World Health Organization (WHO), (1959) Joint WHO/FAO Expert committee on Zoonoses, Second report, Tech Rep Ser No. 169, WHO, Geneva.

9. Taylor, L.H., Latham, S.M. and Woolhouse, M.E.J. (2001) Risk factors for human disease emergence. Phil. Trans. R. Soc. Lond. B, 356: 983-989.

10. Jones, K. E., Patel, N.G., Levy, M. A., Storeygard, A., Balk, D., Gittleman, J. L. and Daszak, P. (2008) Global trends in emerging infectious diseases. Nature, 451(7181): 990-993.

11. The Hindu, (2012) Monkey fever contained in Bandipur Tiger Reserve. December 20, 2012.

12. Bengis, R.G., Leighton, F.A., Fischer, J.R., Artois, M., Mörner, T. and Tate, C.M. (2004) The role of wildlife in emerging and re-emerging zoonoses. Revue scientifique et technique, 23(2): 497-511.

13. Cutler, S.J., Fooks, A.R. and Van der Poel, W.H.M. (2010). Public health threat of new, reemerging, and neglected zoonoses in the industrialized world. Emerg Infect Dis, 16 (1): $1-7$.

14. Stone, A.C., Wilbur, A.K., Buikstra, J.E. and Roberts, C.A. (2009) Tuberculosis and leprosy in perspective. Am J Phys Anthropol, 49: 66-94.

15. Wild, M.A. and Pape, W.J. (1996) Zoonoses of importance in wildlife rehabilitation. Pp.1-12.

16. MacNeil, A. and Rollin, P.E. (2012) Ebola and Marburg hemorrhagic fevers: Neglected tropical diseases? PLoS Negl Trop Dis, 6(6): e1546 (1-7). doi:10.1371/journal.pntd. 0001546.

17. Nunn, C.L., Thrall, P.H., Stewart, K. and Harcourt, A.H. (2008) Emerging infectious diseases and animal social systems. Evol Ecol, 22: 519-543.

18. Public Health Foundation of India (PHFI), (2008) Report of brainstorming meeting, Road map to combat zoonoses in India organised by Public Health Foundation of India (PHFI). New Delhi, $13^{\text {th }}$ June 2008.

19. Swarup, D., Das, A., Saini, M., Kumar, P., Sharma, A.K. and Pal, A. (2009) Standards, guidelines and protocol on disease diagnosis and cure of wild animals in Indian zoos. Indian Veterinary Research Institute and Central Zoo Authority.

20. McLean, R.G. (1994) Wildlife diseases and humans. The Handbook: Prevention and Control of Wildlife Damage, Paper 38. pp.A25-A41.

21. Epstein, J.H. and Price, J.T. (2009) The significant but understudied impact of pathogen transmission from humans to animals. Mt Sinai J Med, 76: 448-455.

22. Adejinmi, O.J. and Ayinmode, A.B. (2008) Preliminary investigation of zooanthroponosis in a Nigerian zoological garden. Vet Res, 2: 38-41.

23. Kooriyama, T., Okamoto, M., Yoshida, T., Nishida, T., Tsubota, T., Saito, A., Tomonaga, M., Matsuzawa, T., Akari, H., Nishimura, H. and Miyabe-Nishiwaki, T. (2013) Epidemiological study of zoonoses derived from humans in captive chimpanzees. Primates, 54(1): 89-98.

24. Thrusfield, M. (1986) Veterinary epidemiology. Butterworth and company, U.K, 280pp.

25. Thapliyal, D.C. and Misra, D.S. (1996) Fundamentals of animal hygiene and epidemiology. International book distributing company, Lucknow, pp .213.

26. Perlino, C., Hilliard, J. and Koehler, J. (1998) Fatal Cercopithecine herpesvirus 1 (B Virus) infection following a mucocutaneous exposure and interim recommendations for worker protection. Morb Mort Wkly Rep, 47(49): 10731083.

27. Nigam, P. and Srivastav, A. (2011) Assessing occupational hazards among Indian wildlife health professionals. Veterinarski Arhiv, 81:731-741.

28. Trevejo, R.T. (2000) Rabies pre-exposure vaccination among veterinarians and at-risk staff. $J$ Am Vet Med Assoc, 217(11): 1647-1650.

29. Menezes, R. (2008) Rabies in India. Can Med Assoc J, 178(5): 564-566.

30. McLaughlin, J. (2002) Gardens as a source of infectious disease: Reducing the risk. Available from http://miamidade.ifas.ufl.edu/pdfs/urban_hort/Gardening-InfectiousDisease. Accessed on 12-02-2013.

31. Rhyan, J.C. and Spraker, T.R. (2010) Emergence of diseases from wildlife reservoirs. Vet Pathol, 47(1): 34-39.

32. Warwick, C., Arena, P.C., Steedman, C. and Jessop, M. (2012) A review of captive exotic animal-linked zoonoses. $J$ Env Health Res, 12(1): 9-24.

33. Rietschel, W. (1998) Zoonoses in primates in zoological gardens (including zoo-staff). Europ Ass of Zoo and Wildlife Vet, Second scientific meeting, May 21-24, 1998, Chester, United Kingdom.

34. Janssen, D., Lamberski, N., Dunne, G., Ginsberg, M., Roach, C., Tweeten, S., Gorwitz, R., Waterman, S., Bensyl, D. and Sugerman, D. (2009) Methicillin-Resistant Staphylococcus aureus skin infections from an elephant calf- San Diego, California, 2008. Morb Mort Wkly Rep, 58(08): 194-198.

35. Epp, T. and Waldner, C. (2012) Occupational health hazards in veterinary medicine: Zoonoses and other biological hazards. Can Vet J, 53(2): 144-50.

36. Siembieda, J.L., Miller, W.A., Byrne, B.A., Ziccardi, M.H., Anderson, N., Chouicha, N., Sandrock, C.E. and Johnson, C.K. (2011) Zoonotic pathogens isolated from wild animals and environmental samples at two California wildlife hospitals. JAm Vet MedAssoc, 238(6): 773-83.

37. Centers for Disease Control and Prevention (CDC), (2007) Compendium of measures to prevent disease associated with animals in public settings. Morb Mort Wkly Rep, 56 (5): 1-15.

38. Friedman, C.R., Torigian, C., Shillam, P.J., Hoffman, R.E., Heltze, D., Beebe, J.L., Malcolm, G., DeWitt, W.E., Hutwagner, L. and Griffin, P.M. (1998) An outbreak of Salmonellosis among children attending a reptile exhibit at a zoo. Jpaediatr, 132(5): 802-807.

39. Crump, J.A., Braden, C.R., Dey, M.E., Hoekstra, R.M., Rickelman-Apisa, J.M., Baldwin, D.A., De Fijter, S.J., Nowicki, S.F., Koch, E.M., Bannerman, T.L., Smith, F.W., Sarisky, J.P., Hochberg, N. and Mead, P.S. (2003) Outbreaks of Escherichia coli O157 infections at multiple county agricultural fairs: a hazard of mixing cattle, concession stands and children. Epidemiol Infect, 131: 1055-62.

40. Chertow, D. (2006) Outbreak of Escherichia coli O157:H7 related to direct and indirect animal contact in petting zoos Florida, 2005. In: Programs and abstracts of the $55^{\text {th }}$ annual epidemic intelligence service conference, $24-28^{\text {th }}$ April 2006, Atlanta, GA.

41. Lederer, I., Much, P. and Allerberger, F. (2005) Outbreak of shigellosis in the Vienna zoo affecting human and nonhuman primates. Int J Infect Dis, 9: 290-291.

42. Matsui, T., Nakashima, K., Ohyama, T., Kobayashi, J., Arima, Y., Kishimoto, T., Ogawa, M., Cai, Y., Shiga, S., Ando, S., Kurane, I., Tabara, K., Itagaki, A., Nitta, N., Fukushi, H., Matsumoto, A. and Okabe, N. (2008) An outbreak of psittacosis in a bird park in Japan. Epidemiol Infect, 136: 492-495.

43. Lijima, Y., Akiyoshi, K., Tanaka, S., Nukina, M., Ito, M., Haruta, T., Inoue, A., Andoand, S. and Kishimoto, T. (2009) Psittacosis outbreak at an avian exhibition. Kansenshogaku Zasshi, 83(5): 500-505.

44. National Institute of Infectious Diseases (NIID), (2002) Psittacosis in Japan, 1999-2002. Infectious Agents Surveillance Report, 2002, 23: 245-246.

45. Association for Prevention and Control of Rabies in India (APCRI), (2004) Assessing burden of rabies in India. WHO sponsored National multi-centric rabies survey, 2003. Final report. pp.1-102.

46. Vorou, R.M., Papavassiliou, V.G. and Tsiodras, S. (2007) Emerging zoonoses and vector-borne infections affecting 
humans in Europe. Epidemiol Infect, 135(8): 1231-1247.

47. Pfeffer, M. and Dobler, G. (2010) Emergence of zoonotic arboviruses by animal trade and migration. Parasit Vectors, 3: 35 .

48. Prajapati, D.S., Patel, K.M., Patel, R.K., Sen, D.J., Patel, J.S. and Garg, C.S. (2011) Crimean-Congo Hemorrhagic Fever from tick-borne viral disease. IJCP, 3 (02): 1-6.

49. Leggat, P.A., Smith, D.R. and Speare, R. (2009) Exposure rate of needle stick and sharps injuries among Australian veterinarians. JOccup Med Toxicol, 4: 25 .

50. Artenstein, A.W., Hicks, C.B., Goodwin Jr, B.S. and Hilliard, J.K. (1991) Human infection with B virus following a needle stick injury. Rev Infect Dis, 13(2): 288-91.

51. Ramsey, D. (1994) Blastomycosis in a veterinarian. J Am Vet MedAssoc, 205(7): 968.

52. Simmert, J., Heckel, J.O., Rietschel, W., Kimmig, P. and Stinr, R. (1998) Zoonotic aspects of a Coxiella burnetii infection in farmed fallow deer (dama dama) a case report. European Association of Zoo- and Wildlife Veterinarians, second scientific meeting, May 21-24, 1998, Chester, UK.

53. Stetter, M. D., Mikota, S.K., Gutter, A.F., Monterroso, E.R., Dalovisio, J.R., Degraw, C. and Farley, T. (1995) Epizootic of Mycobacterium bovis in a zoologic park. J Am Vet Med Assoc, 207(12): 1618-21.

54. Michalak, K., Austin, C., Diesel, S., Bacon, J.M., Zimmerman, P. and Maslow, J.N. (1998) Mycobacterium tuberculosis infection as a zoonotic disease: transmission between humans and elephants. Emerg Infect Dis, 4(2): 283287.

55. Fine, P., Eames, K., and Heymann, D. L. (2011) "Herd Immunity": A Rough Guide. Clin Infect Dis, 52 (7):911-916.

56. Wobeser, G. (2002) Disease management strategies for wildlife. Rev sci tech Off int Epiz, 21(1): 159-178.

57. Hostnik, P., Rihtari Danijela., Grom, J., Malovrh, T. and Toplak, I. (2011) Maintenance and control of the vaccination belt along neighbouring Rabies infected area. Acta Veterinaria (Beograd), 61(2-3): 163-174.

58. Blancou, J., Artois, M., Gilot-Fromont, E., Kaden, V., Rossi, S., Smith, G.C., Hutchings, M.R., Chambers, M.A., Houghton, S. and Delahay, R.J. (2009) Options for the Control of Disease 1: Targeting the infectious or parasitic agent. In: Delahay, R.J., Smith, G.C., Hutchings, M.R., editors. Management of Disease in Wild Mammals. Springer, Tokyo, Berlin, Heidelberg, New York, pp. 97-120.

59. Atanaskova, E., Kochevski, Z., Stefanovska, J. and Nikolovski, G. (2011) Endoparasites in wild animals at the zoological garden in Skopje, Macedonia. JOTT, 3(7): 1955-1958.

60. Ward, A.I., VerCauteren, K.C., Walter, W.D., Gilot-Fromont, E., Rossi, S., Edwards-Jones, G., Lambert, M.S., Hutchings, M.R. and Delahay, R.J. (2009) Options for the control of disease 3: Targeting the environment. In: Delahay, R.J., Smith, G.C., Hutchings, M.R., editors. Management of Disease in Wild Mammals. Springer, Tokyo, Berlin, Heidelberg, New York, pp. 147-168.
61. Ramirez, K. (2002) Animal training, an overlooked science: bringing training out of the closet. Proc Am Assoc Zoo Vet 2002; Milwaukee, WI, pp. 40-44.

62. World Organisation for Animal Health (OIE), (2010) Training manual on wildlife diseases and surveillance. Workshop for OIE national focal points for wildlife. Paris, France, pp. 1-46.

63. Alum, A., Rubino, J.R. and Ijaz, M.K. (2010) The global war against intestinal parasites-should we use a holistic approach? Int JInfect Dis, 14: e732-e738.

64. Vahedi, F., Moazeni Jula, G., Kianizadeh, M. and Mahmoudi, M. (2009) Characterization of Bacillus anthracis spores isolates from soil by biochemical and multiplex PCR analysis. East Mediterr Health J, 15(1): 149156.

65. Centers for Disease Control and Prevention (CDC), (2003) Epidemic/Epizootic West Nile Virus in the United States: guidelines for surveillance, prevention, and control. $3^{\text {rd }}$ revision. 1-78. Available from http://www.cdc.gov/ncidod/ $\mathrm{dvbid} /$ westnile/resources/wnv-guidelines-apr-2001. Accessed on $10 / 1 / 2013$.

66. Vallat, B. (2008) Surveiller la faune sauvage pour mieux la protéger et pour nous prémunir des maladies qu'elle nous transmet. Bull OIE, (3): 1-3.

67. Artois, M., Blancou, J., Dupeyroux, O. and Gilot-Fromont, E. (2011) Sustainable control of zoonotic pathogens in wildlife: how to be fair to wild animals? Rev sci tech Off int Epiz, 30 (3): 733-743.

68. Scheftel, J.M., Elchos, B.L., Cherry, B., DeBess, E.E., Hopkins, S.G., Levine, J.F., Williams, C.J., Bell, M.R., Dvorak, G.D., Funk, R.H., Just, S.D., Samples, O.M., Schaefer, E.C. and Silvia, C.A. (2010) Compendium of veterinary standard precautions for zoonotic disease prevention in veterinary personnel: National Association of State Public Health Veterinarians, veterinary infection control committee. J Am Vet Med Assoc, 237(12): 14031422.

69. Centarl Zoo Authority (CZA), (2009) Zoos in Indialegislation, policy, guidelines \& strategies, pp. 1-1033.

70. Miller, J.M., Astles, R., Baszler, T., Carey, R., Garcia, L., Gray, L., Larone, D., Pentella, M., Pollock, A., Shapiro, D.S., Weirich, E. and Wiedbrauk, D. (2012) Guidelines for safe work practices in human and animal medical diagnostic laboratories. Recommendations of a CDC-convened, Biosafety Blue Ribbon Panel. MMWR Surveill Summ, 61:1102.

71. Saito, E.K. and Shreve, A.A. (2005) Survey of wildlife rehabilitators on infection control and personal protective behaviors. Wildlife Rehabilitation Bulletin, 23(2): 42-46.

72. Paul Duff, (2003) Wildlife disease surveillance by the veterinary laboratory agency. Microbiology Today, 30: 157159.

73. Aguirre, A.A. (2009) Essential veterinary education in zoological and wildlife medicine: a global perspective. Rev. sci.tech. Off. int. Epiz, 28 (2): 605-610. 